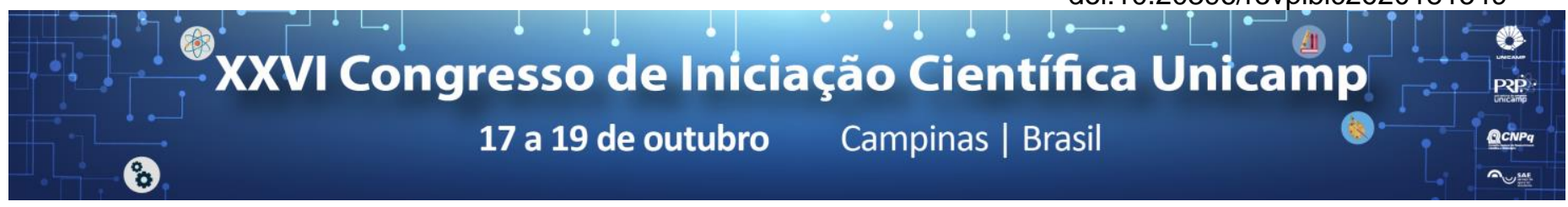

\title{
ANISOTROPIA DE ROCHAS POR MEIO DA CARACTERIZAÇÃO POR ULTRASSOM
}

\author{
Vinícius A. A. Pereira*, Cinthya B. Pedroso, Recieli K. dos Santos
}

\section{Resumo}

A dificuldade de obtenção dos parâmetros elásticos de um material depende da sua complexidade em termos de anisotropia elástica, que o caracteriza quanto a sua resposta aos esforços nas diferentes direções. A anisotropia das rochas é discutida em vários estudos, sendo que muitos deles apresentam resultados de caracterização adotando-a como isotrópica, porém muitos autores citam anisotropia fraca apresentada por esse material. Sendo assim, o objetivo desse projeto foi a caracterização de rochas por ultrassom considerando diferentes condições de anisotropia. A caracterização das rochas foi realizada em corpos de prova poliedricos com utilização de equipamento de ultrassom e transdutores de compressão e de cisalhamento de $1,0 \mathrm{MHz}$ de frequência. A caracterização elástica apresentou maiores valores para os parâmetros elásticos, módulos de elasticidade - $E$ e de cisalhamento - $G$, para a rocha estratificada, seguida da rocha PD e as menores propriedades foram apresentadas pela rocha Atol. O coeficiente de Poisson médio, considerando os três tipos de rocha, foi de 0,27 . Independente do comportamento elástico adotado nas análises, não houve diferenças estatisticamente significativas nos parâmetros elásticos nos três eixos de simetria, classificando o material como isotópico.

Palavras-chave: ortotropia, isotropia transversal, módulo de elasticidade, coeficiente de Poisson.

\section{Introdução}

Ensaios de propagação de ondas permitem obter parâmetros elásticos em diferentes direções de um material. O material ortotrópico é considerado como sendo o mais complexo, e sua caracterização pode ser obtida através da utilização de um único corpo de prova poliédrico de 26 faces. Para rochas, ainda não há um consenso sobre 0 seu comportamento elástico (anisotropia). O objetivo dessa pesquisa, portanto, foi caracterizar rochas por ultrassom considerando diferentes condições de anisotropia (ortotropia, isotropia transversal e isotropia).

\section{Resultados e Discussão}

Os ensaios de ultrassom foram realizados em 14 poliedros de 26 faces, oriundos de 3 tipos de rochas (estratificadas, Atol e PD). Para os ensaios foram utilizados trandutores de compressão e cisalhamenteo de $1 \mathrm{MHz}$.

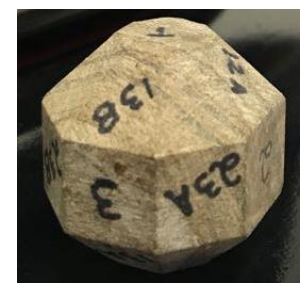

a

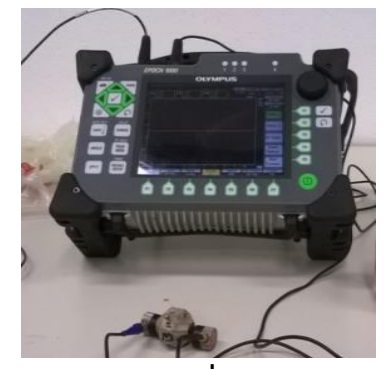

b
Figura 1. Poliedro de 26 faces de rocha (a) e ensaio de ultrassom em um poliedro de rocha (b).

Para as análises realizadas considerando as rochas com comportamento ortotrópico e isotrópico transversalmente, os baixos valores de coeficientes de variação das médias dos parâmetros nas três direções (ortotropia) ou nas duas direções (isotropia transversal) avaliadas, já deram indício de isotropia das rochas, comportamento que foi confirmado pelas análises estatísticas, as quais não apresentaram diferenças estatisticamente significativas (com 95\% de nível de confiança) para os três eixos de simetria, quando a rocha foi considerada como material ortotrópico, nem para os dois eixos de simetria, quando a rocha foi considerada como material com isotropia transversal.

A caracterização elástica apresentou maiores valores para os parâmetros elásticos, módulos de elasticidade -E e de cisalhamento - G, para a rocha estratificada, seguida da rocha PD e as menores propriedades foram apresentadas pela rocha Atol. O coeficiente de Poisson médio, considerando os três tipos de rocha, foi de 0,27.

Tabela 1. Parâmetros elásticos médios e coeficientes de variação $(\mathrm{CV})$ das rochas analisadas na pesquisa caracterização considerando a rocha como material isotrópico.

\begin{tabular}{ccccccc}
\hline Parâmetros & \multicolumn{2}{c}{ Estratificada } & \multicolumn{2}{c}{ PD } & \multicolumn{2}{c}{ Atol } \\
\cline { 2 - 7 } elásticos & Média & CV (\%) & Média & CV (\%) & Média & CV (\%) \\
\hline E (MPa) & 50576 & 11 & 32439 & 6 & 18783 & 21 \\
G (MPa) & 19904 & 11 & 12988 & 4 & 7208 & 21 \\
v & 0,27 & 5 & 0,25 & 11 & 0,30 & 1 \\
\hline
\end{tabular}

\section{Conclusões}

A avaliação do comportamento anisotrópico indicou isotropia para três tipos de rochas avaliadas, pois independente do comportamento elástico adotado nas análises: não houve diferenças estatisticamente significativas nos parâmetros elásticos nos três eixos de simetria.

\section{Agradecimentos}

À Recieli K. dos Santos e à Mônica Ruy pelo apoio e incentivo prestados durante a pesquisa, à professora Dra. Cinthya Bertoldo pela oportunidade da realização da pesquisa e à minha amiga Rafaela M. Leite no auxílio das atividades.

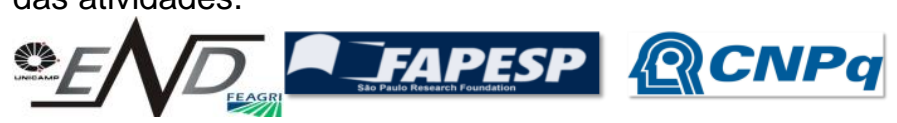

